\title{
ANALISIS GAMBAR BERTEMA KEGEMARAN DI RUMAH KARYA MURID KELAS V SD NEGERI 064023 MEDAN TUNTUNGAN
}

\author{
Agraini Oktavia Larosa ${ }^{*}$, Agus Priyatno $^{2 *}$, Onggal Sihite $^{3^{*}}$ \\ Program Studi Pendidikan Seni Rupa Jurusan Seni Rupa Fakultas Bahasa dan Seni \\ Universitas Negeri Medan \\ Jl. Willem Iskandar Pasar V Medan Estate, Kec, Percut Sei Tuan, Kab. Deli Serdang, Kode Pos 20371 \\ Sumatera Utara. Indonesia \\ Email: agrainilarosa95@gmail.com
}

\begin{abstract}
Abstrak
Penelitian ini dilatarbelakangi oleh keunikan pada gambar anak pada tahap periodesasi masa realisme awal berdasarkan teori Viktor Lowenfeld dan Lambert Britain. Tujuan penelitian ini adalah untuk mengetahui kemampuan murid kelas V SD Negeri 064023 Medan Tuntungan dalam menerapkan gambar bertema "kegemaran di rumah" berdasrkan 3 aspek yaitu, bentuk, warna dan komposisi dilandasi oleh teori periodesasi. Metode penelitian ini adalah deskriptif kualitatif, dimana data dari seluruh instrumen penelitian dideskripsikan sesuai dengan teori periodesai. Hasil penelitian menyimpulkan bahwa seluruh karya murid kelas V SD Negeri 064023 Medan Tuntungan sudah sesuai dengan teori periodesasi oleh Viktor Lowenfeld dan Lambert Britain yang dilihat dari bentuk, warna dan komposisinya. Jika dilihat dari hasil murid menerapkan tema gambar "kegemaran anak di rumah", terdapat 4 karya sudah sesuai dengan tema, dengan masing - masing karya terdapat tema belajar, bermain, membantu orang tua, dan menonton televisi.
\end{abstract}

Kata Kunci: bentuk, warna, komposisi, tema, periodesasi.

\begin{abstract}
This research is motivated by the uniqueness of children's art at the period of periodization of the period of the dawning realism based on the theories of Viktor Lowenfeld and Lambert Britain.. The purpose of this study was to determine the ability of the fifth grade students of SD Negeri 064023 Medan Tuntungan to apply draw with theme "favorite activity at home" based on 3 aspects, namely, the form, color and composition based on the theory of periodization. This research method is descriptive qualitative, where data from all research instruments are described according to the periodical theory. The results of the study concluded that all the works of the fifth grade students of SD Negeri 064023 Medan Tuntungan were in accordance with the theory of periodization by Viktor Lowenfeld and Lambert Britain which were seen from their shape, color and composition. If seen from the results of students applying the theme of the draw "favorite activity at home ", there are 4 works in accordance with the theme, with each work there are themes of learning, playing, helping parents, and watching television.
\end{abstract}

Keywords: shape, color, composition, theme, periodization.

\section{PENDAHULUAN}

Dalam menunjang kebutuhan dan untuk mengetahui serta memahami kerakteristik anak, maka seorang pendidik seni perlu mempelajari karakteristik gambar anak bedasarkan periodesasi perkembangan yang dikemukakan oleh para ahli di bidang pendidikan seni rupa anak. Pembagian masa atau periodesasi dimaksudkan untuk lebih mengenal karya seni rupa anak dalam hal melakukan kegiatan dan penilaian. Jika dilihat dari masa perkembangan seni anak untuk kelas V SD dengan umur sekitar 10 atau 11 tahun maka masuk dalam tahap periodesasi pada masa "realisme awal (the dawning realism) oleh Viktor Lowenfeld.

Karakteristik gambar anak berdasaran teori periodesasinya dapat dilihat dari perkembangan persepsi anak terhadap bentuk, warna, dan komposisi. Pada periodesasi masa realisme awal bentuk yang digambarkan anak sudah dapat dikenali bentuknya, dalam meniru bentuk alam, tampak sudah mendekati kenyataan (realitas), terlihat adanya menghias (dekorasi) objek gambar, anak mulai mengekspresikan objek gambar dengan karakter tertentu, lelaki atau perempuan, dan sebaginya. 
Berdasarkan warna yang sesuai dengan tahap periodesasi masa realsime awal adalah seperti, karakteristik warna mulai mendapat perhatian, walaupun belum adanya penampilan dalam hal perubahan efek warna seperti gelap terang dan bayangan dan pemahan warna sudah mulai disadari, misalnya sudah mulai mampu membedakan antara warna biru langit dengan biru air laut. Maka berdasarkan teori Viktor Lowenfeld juga peneliti menerapkan pewarnaan teknik kering yang dimana menggunakan cat poster. Hal ini dikarenakan murid menggunakan alat mewarnai dengan pensil warna pada pembelajaran menggambar sebelumnya, ini membuat dalam pewarnaan menjadi terbatas dengan warna yang ada saja. Berdasarkan periodesasi pada masa realisme awal oleh Viktor Lawenfeld menyatakan bahwa pada usia anak 9-11 tahun baiknya menggunakan alat dalam mewarnai dengan cat poster yang dapat memberi kebebasan pada murid untuk menghasilkan warna sendiri dengan pencampuran warna. Murid akan diberikan warna primer saja, maka dengan warna itu murid dapat melalukan pencampuran warna sendiri.

Berdasarkan teori periodesasi masa realisme awal, maka komposisi yang dimaksudkan dalam hal ini bagaimana menampilkan kesan ruang, yang mana anak tidak lagi bertumpu pada garis dasar melainkan pada bidang dasar dan mulai adanya keseimbangan.

Berdasarkan 3 aspek ini peneliti ingin mengetahui kemampuan murid dalam menerapkannya pada hasil karya gambar bertema "kegemaran anak di rumah pada karya murid kelas V SD Negeri 064023 Medan Tuntungan dengan berdasarkan pada teorti periodesasi masa "Realisme Awal (The Dawning Realism) oleh Viktor Lowenfeld dan Lambert Britain.

\section{KAJIAN TEORI}

\section{Menggambar pada Anak}

Menurut Pamadhi (2003:8.6) "menggambar adalah memindahkan objek dengan mencoret dalam medium dua dimensi, berupa kertas, kanvas, atau media datar".

Menurut William (2013 : 269) dalam bukunya handbook of drawing menjelaskan bahwa "the chief purpose in letting a young child draw is that it may not lose the power of seeing things as they appear, whilst at the same time it is learning what their shapes really are". Tujuan utama dalam membiarkan anak kecil menggambar adalah bahwa agar tidak kehilangan kemampuan dalam melihat hal - hal yang tampak, sementara pada saat yang sama ia belajar bentuk sebenarnya.

\section{Bentuk}

Istilah "Bentuk" berasal dari bahasa Indonesia yang berarti bangun (shape) atau bentuk plastis (form). Kata bentuk dalam seni rupa diartikan sebagai wujud yang terdapat di alam dan tampak nyata. Bentuk plastis ialah bentuk benda sebagaimana terlihat dan terasa karena adanya unsur nilai (value) gelap terang, sehingga kehadiran benda itu tampak dan terasa lebih hidup misalnya membuat bentuk manusia, binatang, dan sebagainya (Nawawi. 2005: 155- 156).

\section{Warna}

Warna merupakan unsur gambar yang sangat penting. Warna akan dapat mewakili ungkapan secara lebih lengkap daripada unsur lain, lebih - lebih bagi anak anak kecil,Sehubungan dengan pemakaian warna dalam gambar buatan anak kecil, kita dapat membedakan tiga cara pemakaian warna dalam gambar buatan anak kecil, kita dapat membedakan tiga cara pemakaian. Ketiga cara itu ialah pemakaian secara pilihan random, penentuan secara emosional, dan pemilihan secara serebralis (Garha, 1980).

\section{Komposisi}

Menurut pamadhi (2003: 8.7) dalam buku pendidikan seni di SD "komposisi adalah susunan benda - benda yang disusun sebagai objek yang dilihat. Namun, kalau benda yang akan digambar dalam posisi diam, maka perupa harus bergerak menyesuaikan posisi menggambar untuk kenyamanannya."

\section{Tema Kegemaran di Rumah}

Ditemukan beberapa kegiatan dari tema kegemaran anak di rumah yang sering di lakukan oleh anak pada kelas V SD Negeri 064032 Medan Tuntungan antara lain, kegiatan belajar, kegiatan bermain, kegiatan kegiatan membantu orang tuadan kegiatan menonton.

\section{Periodesasi Gambar Anak}

Karakteristik gambar dari anak pada usia masa realisme awal ini sebagai berikut: Karya gambar pada anak usia ini lebih menyerupai kenyataan, Kesadaran perspektif mulai muncul. Kesadaran untuk berkelompok dengan teman sebaya dialami pada masa ini. Dalam menggambar objek, proporsi (perbandingan ukuran) belum di kuasai sepenuhnya. Pemahaman warna sudah mulai disadari, warna sudah sesuai dengan warna objek yang sesungguhnya. Sudah menampilkan bentuk garis - garis geometris. Sudah menampilkan bentuk namun belum detail. Seperti meggambarkan bentuk pakaian namun detail dari lipatan pakaian belum terlihat. Kesan ruang sudah dikenal mulai ditemukan garis horizontal. 


\section{METODE PENELITIAN}

Penelitian ini dilaksanakan di SD Negeri 064023 Jln. Jamin Ginting Km 12 Kemenangan Tani Kec. Medan Tuntungan. Metode penelitain ini deskriptif kualitatif. Dalam penelitian ini akan dianalisis bagaimana hasil gambar bertema "kegemaran di rumah" meliputi beberapa indikator penilaian yaitu bentuk, warna dan komposisi. Teknik pengumpulan data dalam penelitian ini ada dua yaitu; (a)observasi, dengan mengumpulkan data - data yang diperlukan dalam menganalisis karya murid kelas $\mathrm{V}$ berdasarkan indikator atau 3 aspek penilaian yaitu bentuk, warna dan komposisi. Dimana penilaian di lakukan oleh 3 validator. (b) teknik dokumentasi, untuk menghasilkan foto dokumentasi sebagai bahan lampiran dalam penelitian.

\section{HASIL DAN PEMBAHASAN}

\section{Hasil}

Berdasarkan hasil penelitian karya gambar bertema "kegemarn anak di rumah" karya murid kelas V SD Negeri 064023 Medan maka temuan yang diperoleh dalam penelitian ini yaitu pada penilaian indikator Bentuk, dimana bentuk sudah dapat dikenali dan bentuk - bentuk yang digambarkan anak berasal dari objek nyata yang ada di sekitar alam dan lingkungan anak tinggal. Anak menggambarkan objek dengan bentuk - bentuk geometris. Sudah dapat membedakan bentuk figur manusia laki - laki dan perempuan, namun bentuk yang digambarkan anak belum proporsional sehingga ini sesuai dengan teori periodesasi perkembangan seni anak pada periodesasi "masa realisme awal (the dawning realism)".

Untuk indikator warna secara umum murid sudah dapat menghasilkan warna campuran yang bervariasi, murid sudah memberi warna pada objek gambar sesuai dengan warna objek yang sesungguhnya. Sehingga ini sesuai dengan teori periodesasi perkembangan seni anak pada "masa realisme awal (the dawning realism)". Namun warna yang dihasilkan anak masih terlihat jorok dan kurang tidak rapi.

Pada indikator Komposisi, terlihat pada gambar anak sudah muncul kesadaran akan perspektif namun tidak dengan cara orang dewasa menggambarkan perspektif. Dalam gambar anak untuk memunculkan perspektif anak menggambarkan garis horizontal untuk memunculkan kesan ruang. Namun di beberapa gambar anak belum adanya menampilkan kesan ruang tersebut. Anak menggambarkan objek utama sebagai pemeran utama dalam cerita yang ada gambarnya. Sehingga hal ini sesuia dengan teori periodesasi perkembangan seni anak pada "masa realisme awal (the dawning realism)" yaitu gambar anak menampilkan kesan ruang dengan memeberikan kesan ruang.

Untuk kesesuai tema yaitu "kegemaran dirumah" yang diklasifikasikan menjadi 4 kegiatan yaitu, tema belajar, bermain, menonton tv, dan membantu orang tua, maka masing - masing murid sudah mampu menerapkan tema tersebut dalam hasil karya gambar mereka.

\section{Pembahasan}

\section{1). Karya 1}

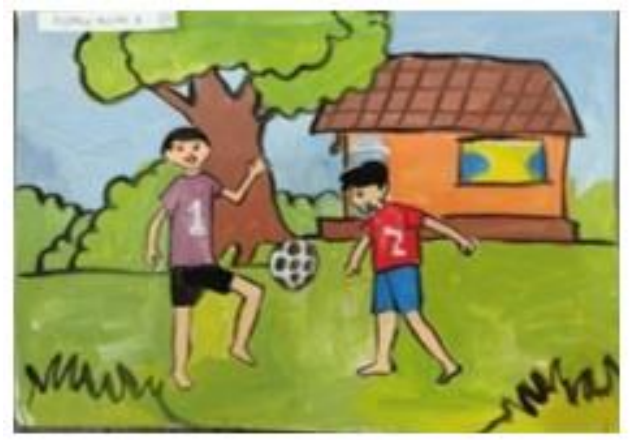

Gambar 1. Tema Bermain, Karya Andrew Berniah (Sumber: Agraini Oktavia Larosa, 2019)

Gambar sudah menampilkan gambar dengan bertema kegemaran di rumah dengan kegiatan bermain, anak mampu menggambarkan bentuk karakter figur namun belum proporsional. Bentuk - bentuk yang digamabarkan sudah dapat dikenali dengan bentuk dari objek - objek nyata disekitar lingkungan anak.

Pada warna dalam gambar ini, anak mampu memberikan warna yang sesuai dengan objek sesungguhnya, warna yang digunakan sudah menampilkan warna campuran seperti hijau, cokelat serta kream. Pewarnaan sudah Dalam gambar ini anak menggunakan teknik pewarnaan secara serebral karena dalam memilih warna sudah ada pertimbangan. Berdasarkan teori periodesasi oleh Viktor Lawenfeld gambar ini sudah termasuk dalam masa realisme awal, sesuai dengan usia perkembangan seni anak anak dengan bentuk yang sudah mirip dengan objek aslinya dan mampu membedakan gambar karakter figur, namun masih terlihat belum proporsional. Dan gambar sudah mengarah ke realistis.

mum diketahui hasil kreativitas gambar dalam mewarnai bergradasi dengan oil pastel oleh Indri Chuang dapat dikategorikan Amat kreatif (A) yaitu dengan perolehan nilai rata-rata 91,4. Untuk mengetahui gambaran secara rinci dapat dijelaskan sebagai berikut: Ditinjau dari aspek pribadi kreatif dengan nilai rata-rata 91 dikategorikan amat bik yaitu 


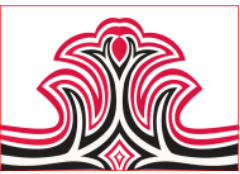

kejelasan dalam pengungkapan ide yang orisinalitas dari individu tersebut amat baik, muncul ide-ide penambahan yang mendukung gambar yang telah diwarnai amat baik, ketekunan dalam proses pewarnaan gambar juga amat baik.

Ditinjau dari aspek press (dorongan) dengan nilai ratarata 90 dikategorikan amat baik yaitu dilihat dari hasil tes lisan dengan wawancara kepada orangtua serta pengajar di Sanggar tingginya dorongan dari diri sendiri serta dorongan dari orangtua yang baik dalam dirinya untuk menghasilkan karya yang amat baik dengan melatih diri di rumah dan di luar sanggar, sering mengikuti perlombaan dan menang di berbagai perlombaan tingkat Kota Pematangsiantar hingga Provinsi, serta tingginya keinginan untuk bertanya kepada guru ketika belajar mewarnai.

Ditinjau dari aspek proses kreatif dengan nilai ratarata 93,5 dikategorikan amat baik yaitu dilihat dari komposisi warna pada karya terlihat amat baik, perpaduan warna yang amat baik, arsiran warna yang terlihat juga amat baik, adanya kejelasan serta variasi arsiran pada karya. Ditijau dari produk kreatif dengan nilai rata-rata 91 dikategorikan amat baik karena ketika ditanya serta wawancara kepada orangtua dan guru di Sanggar, amat baik dalam pengetahuan serta keterampilan mewarnai. Namun kemauan amat baik.

Berdasarkan penguraian nilai rata-rata setiap aspek penilaian dari kreativitas gambar dalam mewarnai bergradasi dengan oil pastel oleh I 340 ing dikategorikan amat kreatif berdasarkan : adi kreatif, press (dorongan), proses kreatif serta produk kreatif. Hasil yang terlihat baik melalui karya gambar yang telah diwarnai bergradasi dengan oil pastel.

\section{2).Karya 2}

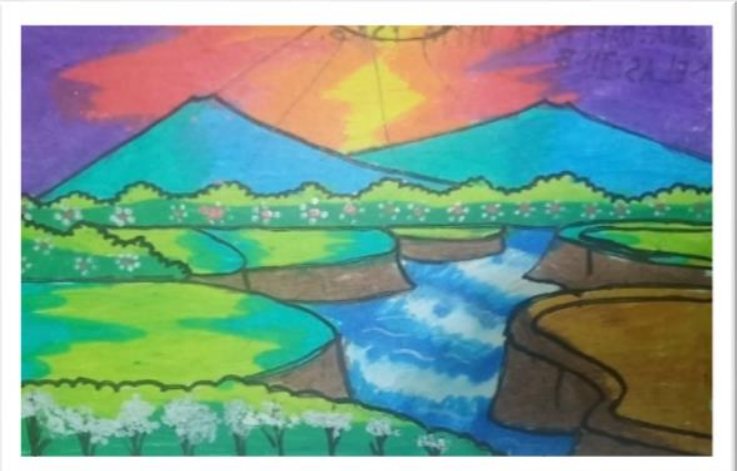

Gambar 2. Karya Dafi Rafa Ditya Pasaribu (Sumber: Siti Yuli Hardianti, 2018)

Secara umum diketahui hasil kreativitas gambar dalam mewarnai bergradasi dengan oil pastel oleh Dafi Rafa
Gorga Jurnal Seni Rupa

Volume 08 Nomor 02 Juli-Desember 2019 p-ISSN: 2301-5942 | e-ISSN: 2580-2380

Ditya Pasaribu dapat dikategorikan kreatif (B) yaitu dengan perolehan nilai rata-rata 80,5. Untuk mengetahui gambaran secara rinci dapat dijelaskan sebagai berikut: Ditinjau dari aspek pribadi kreatif dengan nilai 81,5 dikategorikan baik yaitu kejelasan dalam pengungkapan ide yang orisinalitas dari individu tersebut sudah baik, muncul ide-ide penambahan yang mendukung gambar yang telah diwarnai baik, ketekunan dalam proses pewarnaan gambar juga baik. Ditinjau dari aspek press (dorongan) dengan nilai rata-rata 78 dikategorikan cukup yaitu dilihat dari hasil tes lisan dengan wawancara kepada orangtua serta pengajar di Sanggar masih kurangnya dorongan dari diri sendiri namun dorongan dari orangtua yang baik dalam dirinya untuk menghasilkan karya yang baik dengan melatih diri di rumah, pernah mengikuti perlombaan namun belum pernah menang, serta bertanya kepada guru ketika belajar mewarnai.

Ditinjau dari aspek proses kreatif dengan nilai ratarata 82,5 dikategorikan baik yaitu dilihat dari komposisi warna pada karya terlihat baik, perpaduan warna yang baik, arsiran warna yang terlihat juga baik, adanya kejelasan serta variasi arsiran pada karya. Ditijau dari produk kreatif dengan nilai 80 dikategorikan baik karena ketika ditanya serta wawancara kepada orangtua dan guru di Sanggar, baik dalam pengetahuan serta keterampilan mewarnai. Namun kemauan masih kurang.

Berdasarkan penguraian nilai rata-rata setiap aspek penilaian dari kreativitas gambar dalam mewarnai bergradasi dengan oil pastel oleh Dafi Rafa Ditya Pasaribu dikategorikan kreatif berdasarkan aspek pribadi kreatif, press (dorongan), proses kreatif serta produk kreatif. Hasil yang terlihat baik melalui karya gambar yang telah diwarnai bergradasi dengan oil pastel.

\section{2).Karya 3}

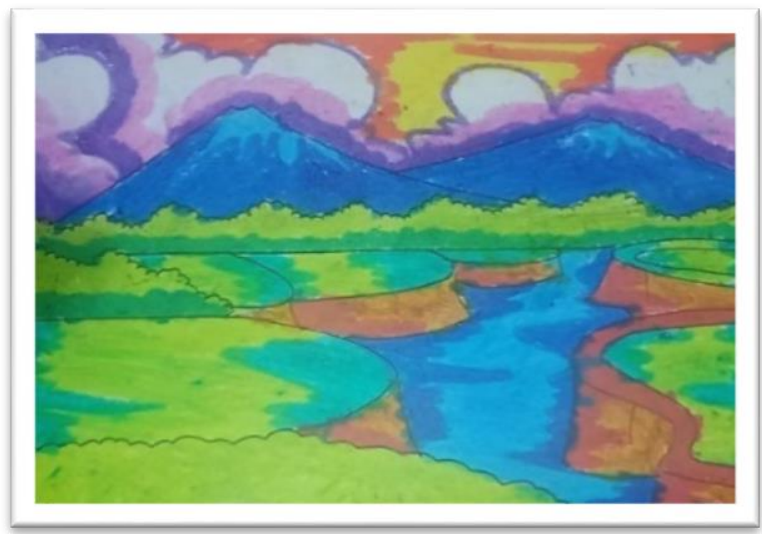

Gambar 3. Karya Grace Saragih 


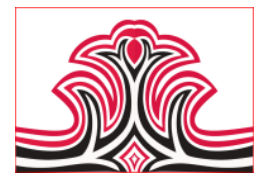

(Sumber: Siti Yuli Hardianti 2018)

Secara umum diketahui hasil kreativitas gambar dalam mewarnai bergradasi dengan oil pastel oleh Grace Saragih dapat dikategorikan Cukup kreatif (C) yaitu dengan perolehan nilai rata-rata 77,9. Untuk mengetahui gambaran secara rinci dapat dijelaskan sebagai berikut: Ditinjau dari aspek pribadi kreatif dengan nilai rata-rata 80,5 dikategorikan baik yaitu kejelasan dalam pengungkapan ide yang orisinalitas dari individu tersebut sudah baik, muncul ide-ide penambahan yang mendukung gambar yang telah diwarnai baik, ketekunan dalam proses pewarnaan gambar juga baik. Ditinjau dari aspek press (dorongan) dengan nilai rata-rata 70 dikategorikan kurang yaitu dilihat dari hasil tes lisan dengan wawancara kepada orangtua serta pengajar di Sanggar masih kurangnya dorongan dari diri sendiri namun masih adanya keraguan dari orangtua terhadap kemampuan yang dimiliki anak, pernah mengikuti perlombaan namun belum pernah menang. Namun masih adanya keingintahuan untuk bertanya kepada guru ketika belajar mewarnai.

Ditinjau dari aspek proses kreatif dengan nilai ratarata 83 dikategorikan baik yaitu dilihat dari komposisi warna pada karya sudah terlihat baik, perpaduan warna yang baik, arsiran warna yang terlihat juga baik, adanya kejelasan serta variasi arsiran pada karya. Ditijau dari produk kreatif dengan nilai 78 dikategorikan cukup baik karena ketika 341 erta wawancara kepada orangtua dan guru _zar, cukup baik dalam pengetahuan serta keterampilan mewarnai. Namun kemauan anak cukup.

Berdasarkan penguraian nilai rata-rata setiap aspek penilaian dari kreativitas gambar dalam mewarnai bergradasi dengan oil pastel oleh Grace Saragih dikategorikan cukup kreatif berdasarkan aspek pribadi kreatif, press (dorongan), proses kreatif serta produk kreatif. Hasil yang terlihat baik melalui karya gambar yang telah diwarnai bergradasi dengan oil pastel.
Gorga Jurnal Seni Rupa

Volume 08 Nomor 02 Juli-Desember 2019 p-ISSN: 2301-5942 | e-ISSN: 2580-2380

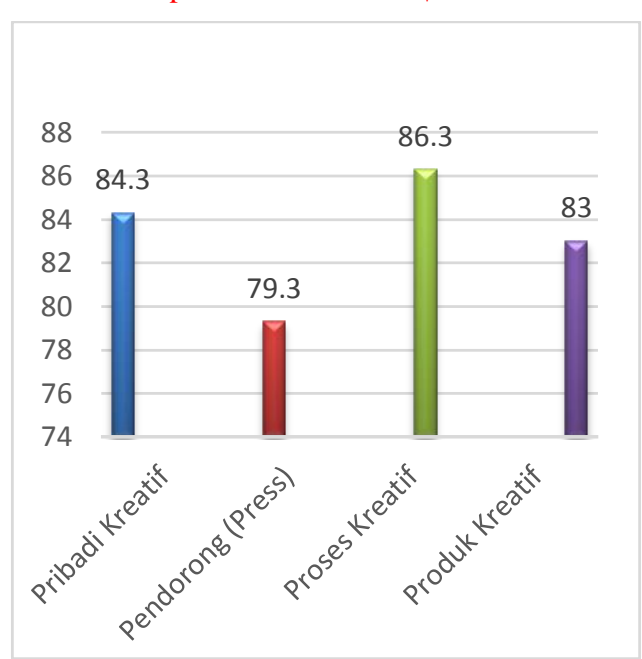

Gambar 4. Hasil Kreativitas Gambar Anak Dalam Mewarnai Bergradasi dengan Menggunakan Oil Pastel Berdasarkan Teori 4P

\section{Pembahasan}

Berdasarkan gambar diatas, terlihat bahwa aspek dorongan mendapatkan nilai terendah. Dorongan merupakan salah satu aspek penting untuk meningkatkan kreativitas anak. Sehingga, untuk lebih meningkatkan kreativitas anak dalam mewarnai bergradasi dengan menggunakan oil pastel di Sanggar Lukis Qalam Jihad Pematangsiantar perlu ditingkatkan dorongan dari luar agar dorongan dari dalam diri sendiri lebih terpancing.

Proses kreatif mendapatkan nilai tertinggi. Proses kreatif terlihat dari pewarnaan gradasi yang dilakukan oleh anak berdasarkan pengetahuan yang telah diajarkan kepada anak selama belajar di sanggar. Sehingga, ajaran guru menjadi patokan pemikiran anak mengenai warna gradasi yang bagus. Berdasarkan hal inilah sehingga menghasilkan produk kreatif yang lebih rendah daripada proses kreatif. Karena, rata-rata ide atau gagasan anak hampir sama yaitu sudah berpatokan kepada pembelajaran guru dibandingkan pengetahuan dan keterampilan yang diberikan selama belajar di sanggar.

\section{KESIMPULAN DAN SARAN 1.Kesimpulan}

(1). Hasil gambar anak dalam pewarnaan bergradasi yang digunakan pada pembelajaran di Sanggar Lukis Qalam Jihad Pematangsiantar dikategorikan baik. (2). Hasil kreativitas gambar anak dalam mewarnai bergradasi dengan menggunakan oil pastel di Sanggar Lukis Qalam Jihad Pematangsiantar berdasarkan beberapa aspek dari teori 4P oleh Utami Munandar yaitu Pribadi kreatif, Pres, Proses kreatif dan Produk kreatif dikategorikan Baik dengan perolehan nilai rata-rata $=83,2$. Dengan demikian, pembelajaran di 
Sanggar Lukis Qalam Jihad Pematangsiantar berkembang dengan baik, perkembangan kreativitas anak yang terlihat secara langsung melalui keterlibatan anak yang aktif serta hasil terlihat jelas dalam pewarnaan bergradasi meggunakan oil pastel.

\section{Saran}

Berdasarkan hasil penelitian, analisis dan kesimpulan penelitian maka peneliti menyarankan: Ketika pembuatan rencana kegiatan pembelajaran sebaiknya dibuat secara rinci dan dicatat tersendiri sehingga mudah di lihat dan dapat digunakan pada lain waktu ketika diperlukan dan dapat merencanakan pembelajaran yang lebih kreatif lagi. Diharapkan agar anak lebih diberikan pengertian bahwa anak dapat mengembangkan kreativitas dan kemauan mereka dalam mewarnai agar anak tidak terpatok pada ajaran guru saja. Diharapkan agar anak lebih diberi press (dorongan) agar menghasilkan karya yang lebih baik lagi dengan memberikan berbagai referensi mewarnai bergradasi dengan oil pastel dari berbagai sumber. Diharapkan penelitian ini menjadi referensi dan dapat dikembangkan pada penelitian selanjutnya yang lebih mendalam terkait tentang: a.Kreativitas anak pada pembelajaran seni rupa yang lebih luas lagi. b.Bahan, alat yang dapat digunakan dalam meningkatkan kreativitas anak dalam mewarnai bergradasi selain oil pastel.

\section{DAFTAR RUJUKAN}

Aziz, Safrudin. (2017). Strategi Pembelajaran Aktif Anak Usia Dini. Yogyakarta: KALIMEDIA.

Doyle, Michael E. (2003). Teknik Pembuatan Gambar Berwarna (Zulkifli Harahap, Penerjemah). Jakarta: Erlangga.

Latuconsina, Hudaya. (2014). Pendidikan Kreatif. Jakarta: Gramedia Pustaka Utama.

Margono. (2009). Metodologi Penelitian Pendidikan. Jakarta: Rineka Cipta.

Mulyasa, H.E. (2014). Manajemen PAUD. Bandung: ROSDA.

Munandar, Utami. (2009). Pengembangan Kreativitas Anak Berbakat. Jakarta: Rineka Cipta.

Nugroho, Eko. (2008). Pengenalan Teori Warna. Yogyakarta: PENERBIT ANDI.

Sugito, dkk. (2017). Metode Penelitian Pendidikan Seni Rupa. Medan: UNIMED PRESS.

Susanto, Mikke. (2011). Diksi Rupa. Yogyakarta: DictiArt Lab, Yogyakarta \& Jagad Art Space, Bali.

Salim, Syahrum. (2015). Metodologi penelitian

Kualitatif. Bandung: Ciptapustaka Media. 